\title{
EIGHTH INTERNATIONAL FESTIVAL OF RED CROSS AND HEALTH FILMS
}

The Eight International Festival of Red Cross and Health Films took place in Varna, Bulgaria, from 9 to 18 June 1979. The festival, which is organized every other year by the Bulgarian Red Cross in co-operation with the League of Red Cross Societies, was held under the auspices of the League, ICRC, WHO and UNESCO.

About 180 films, from 43 countries and five international organizations, were accepted by the selection panel for entry in the festival, which is open to four categories, namely:

A) Red Cross films, produced or commissioned by the international Red Cross institutions or by National Red Cross, Red Crescent and Red Lion and Sun Societies, for education, publicity, information, or furthering interest in the Red Cross.

B) Short and medium-length films dealing with health questions, or problems relating to the prevention of and struggle against pollution of the environment; also, scientific and educational films.

C) Full-length fiction films, dealing with humanitarian or health questions of topical interest.

D) Television programmes.

Among the many notable films, in Category A, the Bulgarian Red Cross President's Grand Prix "Caravelle d'Or" was awarded to "Summer Has Come" (USSR); "Le Club des 6.000" (Belgium) won the League of Red Cross Societies Grand Prix, and the ICRC entry, "African Challenge" was awarded the gold medal in the Red Cross publicity and promotion sub-section. First prizes in Categories B, C, and D went to "Don't worry, it's not serious" (Netherlands), "Knife in the Head" (Federal Republic of Germany), and "Four Women" (Canada).

Besides the competition, the festival offered various other activities, including lectures, seminars and audio-visual presentations, in which 
hundreds of specialists had an opportunity to exchange views and experiences.

With the assistance of the Bulgarian Red Cross, an audio-visual "workshop" was organized by the ICRC and League, in which about a score of National Society representatives took part. Three specialists, all highly conversant with Red Cross problems, had been invited to introduce the discussions: Mr. Luc Chessex (Switzerland) on photography, Dr. George Karpaty (Hungary) on cinema, and Mr. George Nanno (USA) on video-television. The two days during which the participants worked together on various matters in which theory and practice were closely interlinked proved to be most fruitful. They constituted an additional justification for the festival's continued existence by providing an opportunity for relating the analysis of the present production of films to a consideration of future problems.

Faced by needs which continue to increase in number and substance, the Red Cross as a whole will have to make very considerable efforts to cope with present-day requirements. The cinematographic output of most National Societies, of the League and ICRC is severely restricted by lack of funds and technical resources. It is essential to step up co-operation at regional and international level: more joint productions, standardization of equipment, pooling of various kinds of resources, etc. In this connection, a League and ICRC project for the creation of a joint audio-visual centre in Geneva, was favourably greeted by the National Societies' representatives, who expressed the hope that the proposed centre would provide an international platform for the coordination of projects in the field of video television, where it is essential that equipment used by the various producers should be standardized if it is wished to preserve and develop exchange possibilities.

A. $\mathrm{M}$. 